\title{
Optical Sensor for the Detection of $\mathrm{OH}^{-}$ Contamination During Optical Fibre Manufacturing
}

\author{
J-Ph. Besson ${ }^{1}$, S. Schilt ${ }^{1}$, F. Sauser ${ }^{2}$, E. Rochat ${ }^{2}$, Ph. Hamel ${ }^{3}$, \\ F. Sandoz ${ }^{3}$, M. Niklès ${ }^{2}$, L. Thévenaz ${ }^{1}$ \\ ${ }^{1}$ Ecole Polytechnique Fédérale de Lausanne (EPFL), Nanophotonics and Metrology Laboratory, CH-1015 \\ Lausanne, Switzerland \\ ${ }^{2}$ Omnisens SA, Riond-Bosson 3, CH-1110 Morges, Switzerland \\ ${ }^{3}$ Daetwyler Fiber Optics SA, Route de la Gare 70, CH-2017 Boudry, Switzerland \\ Author e-mail address: jean-philippe.besson@epfl.ch
}

\begin{abstract}
Sub-ppm hydrogen chloride $(\mathrm{HCl})$ and water vapour $\left(\mathrm{H}_{2} \mathrm{O}\right)$ monitoring using photoacoustic spectroscopy is reported in optical fibre manufacturing for the production of low-water-peak fibres. Contamination sources of the carrier gas used for fibre preforms manufacturing were identified and discussed.

(C)Optical Society of America

OCIS code: $140.5960 ; 300.6430$
\end{abstract}

\section{Introduction}

Trace gas analysis using laser diode photoacoustic spectroscopy (PAS) is a well established technique suitable for many applications such as environmental monitoring [1] or industrial process control [2,3]. This method enables multi-components analysis, real-time and continuous measurement and provides an excellent linearity over several orders of magnitude and a great selectivity by using single-mode light-emitting sources. In addition, the use of standard semiconductor telecommunication laser diodes in combination with a properly designed photoacoustic (PA) cell enables to reach sub-ppm detection limit for many species.

In this paper, we report a $\mathrm{PA}$ sensor developed to monitor hydrogen chloride $(\mathrm{HCl})$ and water vapour $\left(\mathrm{H}_{2} \mathrm{O}\right)$ at sub-ppm level for process control in the manufacturing of the novel low-water-peak fibres used in optical telecommunications. The presence of a strong $\mathrm{OH}^{-}$absorption peak centered at $1390 \mathrm{~nm}$ in standard silica optical fibres is mainly due to moisture contamination that occurs during the manufacturing process of the fibre preform, usually realised by modified chemical vapour deposition (MCVD). In this process, various gaseous chlorides $\left(\mathrm{SiCl}_{4}, \mathrm{GeCl}_{4}, \mathrm{POCl}_{3}\right)$ are diluted in a carrier gas that flows through a rotating fused silica tube. The carrier gas mainly contains oxygen $\left(\mathrm{O}_{2}\right)$, together with helium $(\mathrm{He})$ at a concentration of a few tens of percent in order to homogenise the gas temperature and therefore to increase the rate deposition of $\mathrm{GeO}_{2}$ and $\mathrm{SiO}_{2}$ on the inner wall of the silica tube. When water contaminations diffuse in the gas mixture, $\mathrm{HCl}$ is produced as a result of the strong reactivity between water and chloride compounds. Measurement of $\mathrm{HCl}$ concentration in the process gas is therefore an excellent indicator of the quantity of water contamimation present in the gas mixture. The developed PA sensor is therefore used as a diagnostic instrument to monitor the quality of the carrier gas after the replacement of a bubbler.

\section{Experimental details and calibration}

The PA sensor is based on resonant PAS in combination with semiconductor laser diodes emitting in the near-infrared region. PAS is described by the periodic absorption of a modulated laser beam tuned on an absorption line of the gas to be detected, so that the absorbed power induces a periodic heating and an acoustic wave is generated through normal thermal expansion. This acoustic wave is detected by a microphone and the signal amplitude is basically proportional to the gas concentration, to the laser power and to the strength of the absorption line. The resonant PA cell consists in three tubes, each operating as an acoustic resonator, terminated by two larger buffer volumes (see Figure 1). This configuration offers the possibility to measure up to three different gases simultaneously using three different lasers (one laser beam per tube). For example, the sensor has been designed to monitor $\mathrm{CH}_{4}, \mathrm{H}_{2} \mathrm{O}$ and $\mathrm{HCl}$ using three DFB lasers emitting respectively in the $1650 \mathrm{~nm}, 1370 \mathrm{~nm}$ and $1740 \mathrm{~nm}$ range. For the on-site measurements reported 


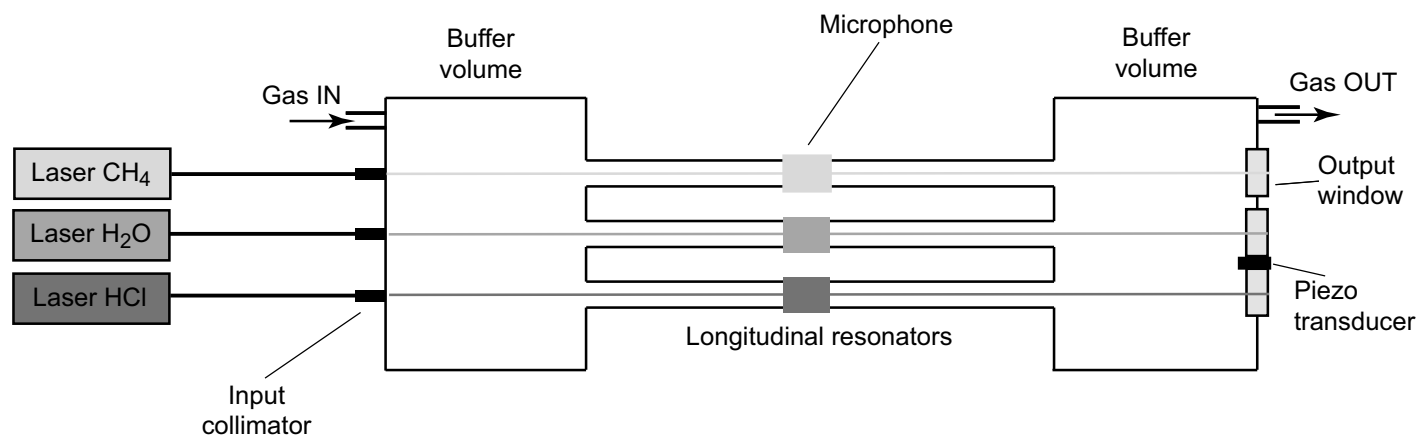

Figure 1: Schematic view of the PA cell consisting in three longitudinal modes operating in their first longitudinal mode. A piezo transducer is used for resonance frequency tracking.

here, methane has not been considered yet and the corresponding laser was simply not connected. Details on the sensor can be found in $[4,5]$.

In order to monitor $\mathrm{HCl}$ and $\mathrm{H}_{2} \mathrm{O}$ concentrations in the carrier gas used in the fibre preform manufacturing, the PA sensor has been inserted in a line parallel to the process line. $\mathrm{HCl}$ and $\mathrm{H}_{2} \mathrm{O}$ were measured during a 11-day period after the insertion of a new $\mathrm{POCl}_{3}$ bubbler in order to evaluate the purge time of the installation. After this time a preform can be manufactured to fulfill the requirements for a low-water-peak fibre. At the end of the campaign, additional measurements were carried out with $\mathrm{SiCl}_{4}$ and $\mathrm{GeCl}_{4}$. A detection limit (defined for a signal-to-noise ratio $\mathrm{SNR}=3$ and with $10 \mathrm{~s}$ integration time) of $60 \mathrm{ppb}$ for $\mathrm{HCl}$ and $35 \mathrm{ppb}$ for $\mathrm{H}_{2} \mathrm{O}$ resulted from these calibrations.

\section{Results and discussion}

A very high concentration of $\mathrm{HCl}$ (up to $0.3 \%$ ) was present immediately after the change of the $\mathrm{POCl}_{3}$ bubbler, showing that the carrier gas was highly contaminated due the change of the $\mathrm{POCl}_{3}$ container. In contrast, the water vapour level was in the ppm range due to the fact that most of the water content present in the gas was readily transformed into $\mathrm{HCl}$. As oxygen was flowing through the $\mathrm{POCl}_{3}$ bubbler, the $\mathrm{HCl}$ concentration decreased along with time due to the purge of the container. The evolution of $\mathrm{H}_{2} \mathrm{O}$ and $\mathrm{HCl}$ concentrations over 11 days is presented in Figure $2 \mathrm{a}$ and $2 \mathrm{~b}$. The variation of $\mathrm{HCl}$ concentration can be
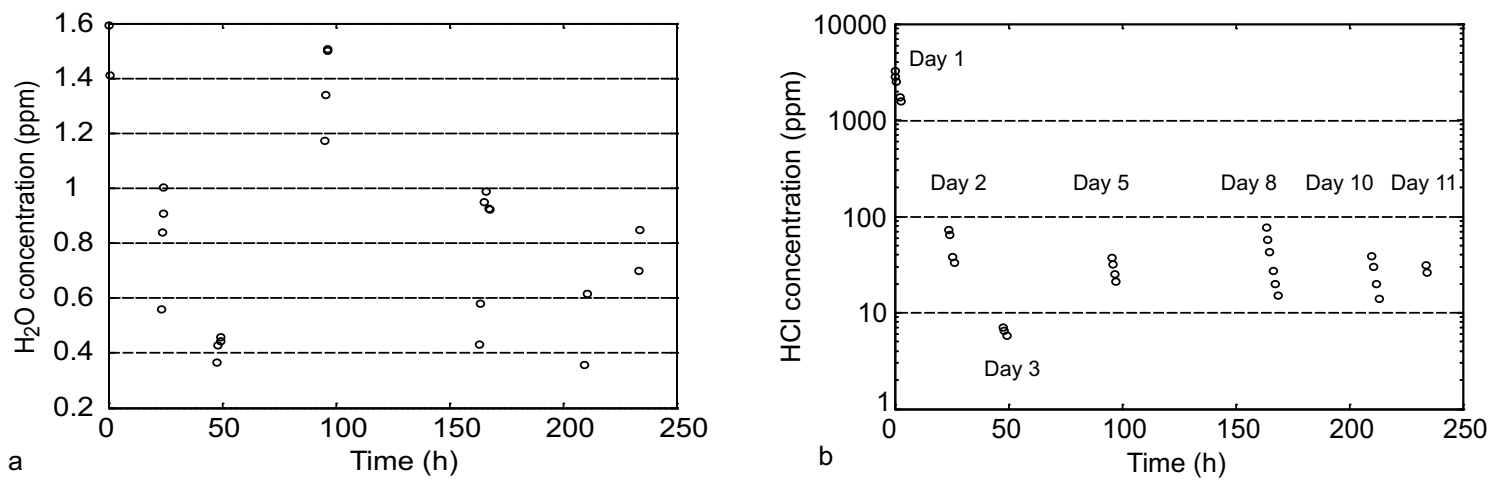

Figure 2: (a) $\mathrm{H}_{2} \mathrm{O}$ and (b) $\mathrm{HCl}$ concentration level evolution over 11 days. The grouped circles represent several measurements performed on the same day during a time period varying from a few tens of minutes up to one hour. Each circle corresponds to one measurement point (integration time of 10s) taken at the beginning or at the end of that period.

understood as follow: on day one, the bubbler was changed, producing a high degree of water contamination transformed into $\mathrm{HCl}$. After continuous purging of the container at $200 \mathrm{sccm}$ of $\mathrm{O}_{2}$ during 49 hours, the concentration decreased to reach a level of $5 \mathrm{ppm}$. No purging and no measurement were performed the 
following day (day four) as a result of a machine maintenance. On day five, a new $\mathrm{HCl}$ concentration was measured at $40 \mathrm{ppm}$ due to water desorption in the teflon head of the container when the $\mathrm{O}_{2}$ purge was interrupted. The concentration decreased down to $21 \mathrm{ppm}$ after 2 hours of purging. After two days break (week-end), the concentration increased again up to $77 \mathrm{ppm}$ to reach a level of $15 \mathrm{ppm}$ after 5 hours of continuous flow of $\mathrm{O}_{2}$. The evolution of water vapour concentration over these days was quite different as the $\mathrm{H}_{2} \mathrm{O}$ concentration changed neither significantly nor in a regular way, from a maximum of $1.6 \mathrm{ppm}$ to a minimum of $0.35 \mathrm{ppm}$. It must be emphasized that the concentration of these contaminants is much lower in the real carrier gas used in the preform manufacturing process, since the total carrier gas mixture is different. The $\mathrm{POCl}_{3}$ concentration in the process is $0.088 \%$ (compared to $2.79 \%$ for the measurements) meaning that $\mathrm{HCl}$ and $\mathrm{H}_{2} \mathrm{O}$ concentrations are reduced accordingly (See Table 1). However, it must be pointed that the sensitivity of the sensor is sufficient to monitor $\mathrm{HCl}$ in the real process gas. After these

Table 1: Comparison of chlorides, $\mathrm{H}_{2} \mathrm{O}$ and $\mathrm{HCl}$ concentrations between the buffer gas used for PAS measurements and the process gas used in optical fibre manufacturing.

\begin{tabular}{lllllll}
\hline \multirow{2}{*}{ Chloride } & \multicolumn{2}{c}{ Chloride concentration (\%) } & \multicolumn{2}{l}{$\mathrm{H}_{2} \mathrm{O}$ concentration $(\mathrm{ppm})$} & \multicolumn{2}{l}{$\mathrm{HCl}$ concentration (ppm) } \\
& Meas. gas & Process gas & Meas. gas & Process gas & Meas. gas & Process gas \\
\hline $\mathrm{POCl}_{3}$ & 2.79 & 0.088 & 0.92 & 0.03 & 15 & 0.47 \\
$\mathrm{SiCl}_{4}$ & 10.31 & 7.85 & - & - & 2.6 & 2 \\
$\mathrm{GeCl}_{4}$ & 2.68 & 2.81 & 0.095 & 0.1 & 0.76 & 0.8 \\
\hline
\end{tabular}

eight days of purging, a first preform has been manufactured and a fibre has been drawn in order to analyse its different parameters, in particular the spectral attenuation. To be compliant with ITU recommendation for a low-water-peak fibre [6], the attenuation measured at the maximum of the $\mathrm{OH}^{-}$peak at $1383 \mathrm{~nm}$ must be lower than the attenuation at $1310 \mathrm{~nm}$ after hydrogen $\left(\mathrm{H}_{2}\right)$ ageing [7]. Attenuation curves of the fibre manufactured from the preform processed on day nine is presented in Figure 3. A second fibre manufactured

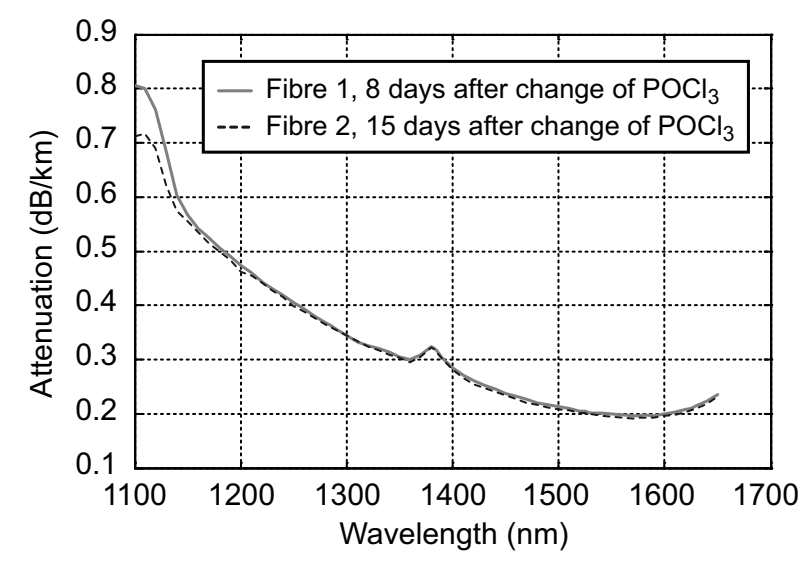

Figure 3: Attenuation of the low-water-peak fibres manufactured 8 days (solid line) and 15 days (dashed line) after the replacement of the $\mathrm{POCl}_{3}$ container.

seven days later is shown on the same figure. These measurements were carried out after the drawing of the fibre, but without performing $\mathrm{H}_{2}$ ageing. However, $\mathrm{H}_{2}$ ageing is not systematically performed and a security margin of $0.02 \mathrm{~dB} / \mathrm{km}$ is added to the attenuation coefficient to take this effect into account. A maximum of $0.34 \mathrm{~dB} / \mathrm{km}$ at $1383 \mathrm{~nm}$ is acceptable for the fibre to be considered as a low-water-peak fibre. On Figure 3, no significant attenuation improvement in the E-band and S-band region can be noticed between the two fibres. In addition, both fibres present an attenuation of $0.320 \mathrm{~dB} / \mathrm{km}$ (fibre of day eight) and $0.318 \mathrm{~dB} / \mathrm{km}$ (fibre of day 15) at $1383 \mathrm{~nm}$, which satisfies the criteria defined above.

Finally, $\mathrm{HCl}$ and $\mathrm{H}_{2} \mathrm{O}$ were monitored in gas mixtures containing $\mathrm{GeCl}_{4}$ and $\mathrm{SiCl}_{4}$ to identify the contribution of these chloride compounds to the $\mathrm{OH}^{-}$peak. The measured concentrations were below 1 ppm for $\mathrm{HCl}$ and around $0.1 \mathrm{ppm}$ for $\mathrm{H}_{2} \mathrm{O}$. The same measurements for $\mathrm{HCl}$ using $\mathrm{SiCl}_{4}$ were performed. 


\section{WB8.pdf}

In order to compare the different contamination sources, typical chloride concentrations present in the process gas are used to extrapolate $\mathrm{HCl}$ and $\mathrm{H}_{2} \mathrm{O}$ concentration from the obtained measurements (see Table 1). The substitution of the $\mathrm{POCl}_{3}$ bubbler results in an $\mathrm{HCl}$ concentration of $15 \mathrm{ppm}$ and a $\mathrm{H}_{2} \mathrm{O}$ concentration of $0.92 \mathrm{ppm}$ (last measured points before preform manufacturing after eight days of purging) corresponding to $0.47 \mathrm{ppm}$ of $\mathrm{HCl}$ and $0.03 \mathrm{ppm}$ of $\mathrm{H}_{2} \mathrm{O}$ in the gas mixture used in the process. $\mathrm{HCl}$ and $\mathrm{H}_{2} \mathrm{O}$ concentrations resulting from the $\mathrm{GeCl}_{4}$ bubbler correspond to $0.76 \mathrm{ppm}$ and $0.10 \mathrm{ppm}$ in the process gas, respectively. Finally, $\mathrm{HCl}$ coming from the $\mathrm{SiCl}_{4}$ container results in a concentration of 2 ppm. This comparison shows that the principal contamination source comes from the $\mathrm{SiCl}_{4}$ container, considering that the purge of the $\mathrm{POCl}_{3}$ bubbler was done during a sufficient period of time.

\section{Conclusion}

Laser diode photoacoustic spectroscopy has demonstrated to be an efficient and reliable measurement technique for trace gas analysis in process gas, especially well adapted to on-line continuous detection and quantification of contamination down to a few tens of ppb. Sensitivity obtained using mW-power laser diodes is sufficient to detect hydrogenated contaminants to a level low enough to secure a zero water-peak fibre production. Such a sensor will undoubtedly be an absolute requirement in the future for the manufacturing of these fibres. Further improvements of the system are under progress aiming at an enhanced signal-to-noise ratio performing at ppb level sensitivity which will still broaden the range of application of the measurement technique.

\section{Acknowledgments}

The authors would like to acknowledge the Commission of Technology and Innovation (CTI) of the Swiss Government for the financial support. The authors are also grateful to NTT Electronics Corporation for providing DFB lasers.

\section{References}

[1] R. A. Rooth, A. J. L. Verhage, and W. Wouters, "Photoacoustic measurement of ammonia in the atmosphere: influence of water vapor and carbon dioxide," Appl. Opt. 29(25), 3643-3653 (1990).

[2] M. W. Sigrist, "Trace gas monitoring by laser photoacoustic spectroscopy and related techniques (plenary)," Review of scientific instruments 74(1), 486-490 (2003).

[3] S. Schilt, L. Thévenaz, M. Niklès, L. Emmenegger, and C. Hüglin, "Ammonia monitoring at trace level using photoacoustic spectroscopy in industrial and environmental applications," spectrochimica Acta A 60(14), 32593268 (2004).

[4] J.-P. Besson, S. Schilt, and L. Thévenaz, "Multi-gas sensing based on photoacoustic spectroscopy using tunable laser diodes," Spectrochimica Acta A 60(14), 3449-3456 (2004).

[5] J.-P. Besson, S. Schilt, and L. Thévenaz, "Sub-ppm multi-gas photoacoustic," Spectrochimica Acta A 63, 899904 (2006)

[6] "Characteristics of a single-mode optical fibre and cable," International Telecommunication Union, ITU-T G652 (2003/03).

[7] "Product specification- sectional specification for class B single mode fiber," International Electrotechnical Commission (IEC), 60793-2-50 (2004-01). 